\title{
Research on Numerical Simulation and Optimization of SCR Flow Field of 200MW Coal-Fired Unit
}

\author{
Yanpeng XU ${ }^{\mathrm{a}}$, Zhiqiang XIA ${ }^{\mathrm{a}}$, Shulan GAN ${ }^{\mathrm{a}}$, Gan $\mathrm{WAN}^{\mathrm{b}}$, Yingsheng $\mathrm{QU}^{\mathrm{b}}$ and Ben \\ WANG $^{\text {b,1 }}$ \\ ${ }^{a}$ Wuhan Haiwang New Energy Engineering\&Technology Co., Ltd, Wuhan, China \\ ${ }^{\mathrm{b}}$ State Key Laboratory of Coal Combustion, Huazhong University of Science and \\ Technology, Wuhan, China
}

\begin{abstract}
In this paper, Computational Fluid Dynamics (CFD) and Flow Model Test are applied to study the flow field of 200MW coal fired power plant, then the optimization program is proposed. Firstly, this paper summarizes some essential design points for SCR reactor system with different structures and different characteristic. Then, the initial flow field of the SCR reactor was simulated to find the defect by the Fluent. Then, optimize the flow fields of velocity of SCR system by adding splitters. In order to improve the mixing degree of flue gas and ammonia, Ammonia Injector Grids (AIG) was designed on the basis of the structure of SCR reactor. Considering the pressure loss and installation space were within allowed limits, a new static mixer was designed to optimize the flow fields of concentration. Through the shift of size, angle and altitude of the static mixer, this paper got a best design project. The research results can provide theoretical support and engineering guidance for the transformation and optimization of the new SCR denitration engineering reaction system.
\end{abstract}

Keywords. Selective catalytic reduction (scr), aig, numerical simulation, optimal design

\section{Introduction}

Coal is an important part of China's energy structure, and this energy structure will be maintained for a long period. Through direct combustion, coal-fired power plants in China emit a large amount of sulfur oxides, nitrogen oxides, and mercury into the atmosphere [1]. These pollutants have caused serious environmental problems and are a major obstacle to the sustainable development of China [2-3]. During the "Thirteenth Five-Year Plan" period, after $\mathrm{SO}_{2}$, NOx has become the top priority in the treatment of pollutants in thermal power plants. As we all know, nitrogen oxides are harmful gases, and the nitrogen oxides produced by the combustion of coal-fired power plants mainly include $\mathrm{NO}$ and $\mathrm{NO}_{2}$ [4]. $\mathrm{NO}$ is a colorless gas, which is easily oxidized in the air and is unstable. It can paralyze the central nervous system of a person. In severe cases, it can cause suffocation and even death. $\mathrm{NO}_{2}$ is reddish-brown and has a pungent odor at

1 Ben Wang, State Key Laboratory of Coal Combustion, Huazhong University of Science and Technology, Wuhan, China; E-mail: benwang@hust.edu.cn. 
room temperature, and its properties are relatively stable. $\mathrm{NO}_{2}$ can damage the human heart, lung, and hematopoietic function, causing emphysema and asthma, and its toxicity is more severe than that of NO [5]. In addition, nitrogen oxides discharged into the atmosphere can also destroy the ozone layer, causing acid rain, causing haze and other catastrophic weather [6]. Therefore, how to effectively control NOx emissions from coal-fired power plants and reduce its environmental hazards has become an urgent problem to be solved.

At present, China has increasingly strict requirements for the emission control of nitrogen oxides from coal-fired power plants. In September 2011, China issued the newly revised "Emission Standards for Air Pollutants for Thermal Power Plants" (GB13223-2011), which has stricter requirements for NOx emissions: Focus on the thermal power industry to carry out NOx pollution prevention and control. New coal-fired thermal power boilers and flue gas denitrification devices must be constructed simultaneously. Before 2015, all existing units must complete the denitrification transformation project and implement the $100 \mathrm{mg} / \mathrm{m} 3$ standard. It can be seen that controlling the emission of nitrogen oxides from thermal power plants has become the top priority of environmental protection in the thermal power industry and is an important part of fulfilling the national emission reduction targets. Selective Catalytic Reduction (SCR) flue gas denitration method is an efficient and mature technology, which has been widely used in the field of pollutant control in power plants at home and abroad [6-7]. In the SCR reaction system, the velocity distribution of the flow field and the mixing uniformity of the reducing agent and the flue gas directly determine the removal efficiency of nitrogen oxides [8].

This research mainly studies the research method of numerical simulation of the flow field of selective catalytic reduction (SCR) denitrification technology. For the reactor of a coal-fired power plant SCR denitrification method (the range includes the horizontal section from the economizer outlet to the air preheater inlet). The entire system) of the fluid flow field is studied and optimized. First, use CFD numerical simulation method for the reactor to analyze the flow field and design the diversion device. After that, a cold-state physical model was built to verify the correctness and reliability of the numerical simulation, and finally a design scheme applied to engineering practice was obtained. It is used to ensure that the flue gas of the denitration project and the reducing agent are uniformly mixed, reduce the ammonia escape rate, and maintain a high denitrification efficiency.

\section{SCR Denitration System and Main Parameters}

In this study, a $2 \times 200 \mathrm{MW}$ coal-fired unit of a self-provided power plant was selected for CFD numerical simulation and optimization research. The project uses liquid ammonia to prepare the reaction reducing agent, a single boiler is equipped with dual SCR reactors, a high temperature and high dust arrangement is adopted, and no economizer temperature bypass and denitrification bypass flue are set. The denitrification device processes $100 \%$ flue gas volume of $2 \times 200 \mathrm{MW}$ units, installs two layers of catalysts and one spare layer. When operating the second-layer catalyst, the flue gas denitration efficiency is not less than $80 \%$. The design coal type of the power plant is Jinjiang lignite, and the check coal type is Huolinhe lignite. The coal quality analysis is shown in table 1 . 
Table 1. Fuel composition and ash melting point analysis.

\begin{tabular}{|c|c|c|c|c|c|}
\hline & Types & Unit & $\begin{array}{l}\text { Design } \\
\text { coal }\end{array}$ & $\begin{array}{l}\text { Check coal } \\
1\end{array}$ & Check coal 2 \\
\hline Test items & Fuel types & & $\begin{array}{l}\text { Jinjiang } \\
\text { Lignite }\end{array}$ & $\begin{array}{l}\text { Huolinhe } \\
\text { lignite }\end{array}$ & $\begin{array}{l}\text { Huolinhe } \\
\text { lignite }\end{array}$ \\
\hline \multirow{5}{*}{$\begin{array}{l}\text { Proximate } \\
\text { analysis }\end{array}$} & $\begin{array}{l}\text { Receipt of total moisture } \\
\text { (Mar) }\end{array}$ & $\%$ & 28.15 & 31 & 31.8 \\
\hline & Air dry base moisture (Mad) & $\%$ & - & - & 5.87 \\
\hline & $\begin{array}{l}\text { Dry ash-free volatile matter } \\
\text { (Vdaf) }\end{array}$ & $\%$ & 42.38 & 49.9 & 48.58 \\
\hline & Received base ash (Aar) & $\%$ & 21.49 & 25.99 & 12.26 \\
\hline & $\begin{array}{l}\text { Received base low calorific } \\
\text { value (Qnet.ar) }\end{array}$ & $\begin{array}{l}\mathrm{MJ} / \\
\mathrm{kg}\end{array}$ & 13.817 & 11.32 & 14.91 \\
\hline \multirow{5}{*}{$\begin{array}{l}\text { Ultimate } \\
\text { analysis }\end{array}$} & $\mathrm{C}$ & $\%$ & 36.7 & 31.15 & 41.29 \\
\hline & $\mathrm{H}$ & $\%$ & 2.98 & 2.37 & 3.12 \\
\hline & $\mathrm{O}$ & $\%$ & 9.6 & 8.45 & 10.54 \\
\hline & $\mathrm{N}$ & $\%$ & 0.62 & 0.54 & 0.81 \\
\hline & $\mathrm{S}$ & $\%$ & 0.46 & 0.5 & 0.18 \\
\hline \multirow{3}{*}{$\begin{array}{l}\text { Ash melting } \\
\text { point analysis }\end{array}$} & $\begin{array}{l}\text { Deformation temperature } \\
\text { (DT) }\end{array}$ & ${ }^{\circ} \mathrm{C}$ & 1200 & - & 1420 \\
\hline & Softening temperature (ST) & ${ }^{\circ} \mathrm{C}$ & $>1300$ & - & 1440 \\
\hline & Flow temperature (FT) & ${ }^{\circ} \mathrm{C}$ & $>1300$ & - & 1460 \\
\hline
\end{tabular}

The coal-fired power plant is equipped with two 200MW coal-fired steam turbine generator sets, the boiler uses Huolinhe lignite, ultra-high-pressure parameters, primary reheating, natural circulation, single furnace, balanced ventilation, solid slag discharge, tightly closed layout, All-steel-framed pulverized coal boiler, boiler platform elevation is $12.6 \mathrm{~m}$, coal feeder floor elevation is $12.6 \mathrm{~m}$. The structure of the SCR denitrification reactor system is shown in figure 1 (a). The main body of the single-sided reactor is $11.5 \mathrm{~m}$ high and $10 \mathrm{~m}$ wide. The inlet is the lower section of the economizer, and the size is $6.2 * 3.2 \mathrm{~m}$. The outlet is connected to the air preheater. It is $3.2 \times 6.6 \mathrm{~m}$. Including the vertical flue, the entire reactor is $24 \mathrm{~m}$ high. The flue gas parameters at the outlet of the economizer and the inlet of the denitrification device are shown in table 2 and table 3 , respectively.
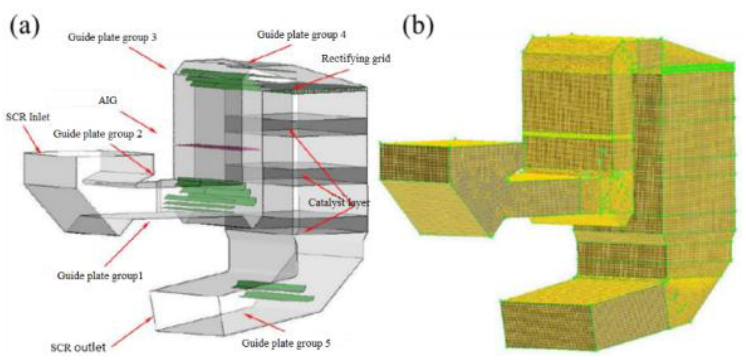

Figure 1. SCR denitration system structure diagram and grid division.

Table 2. Economizer outlet flue gas parameters.

\begin{tabular}{lllllll}
\hline $\begin{array}{l}\text { Project } \\
\text { Unit }\end{array}$ & $\begin{array}{l}\text { Mass Flow } \\
\mathrm{kg} / \mathrm{h}\end{array}$ & $\begin{array}{l}\text { Temperature } \\
{ }^{\circ} \mathrm{C}\end{array}$ & $\begin{array}{l}\mathrm{SO}_{2} \\
\mathrm{mg} / \mathrm{Nm}^{3}\end{array}$ & $\begin{array}{l}\mathrm{SO}_{3} \\
\mathrm{mg} / \mathrm{Nm}^{3}\end{array}$ & $\begin{array}{l}\mathrm{NO}_{\mathrm{x}} \\
\mathrm{mg} / \mathrm{Nm}^{3}\end{array}$ & $\begin{array}{l}\text { Soot concentration } \\
\mathrm{g} / \mathrm{Nm}^{3}\end{array}$ \\
\hline Value & 1003699 & 415 & 1650 & 50 & 400 & 48.3 \\
\hline
\end{tabular}


Table 3. SCR denitrification device flue gas inlet parameters

\begin{tabular}{llllllll}
\hline Project & Unit & $\begin{array}{l}\text { B-MC } \\
\mathrm{R}\end{array}$ & BRL & THA & 70THA & 50THA & HPO \\
\hline $\begin{array}{l}\text { Excessive inlet for } \\
\text { denitrification }\end{array}$ & $/$ & 1.2 & 1.2 & 1.2 & 1.252 & 1.227 & 1.2 \\
Mass Flow & $\mathrm{kg} / \mathrm{h}$ & 100369 & 956942 & 903187 & 709266 & 486122 & 925245 \\
$\begin{array}{l}\text { Temperature } \\
\text { Water content }\end{array}$ & ${ }^{\circ} \mathrm{C}$ & 415 & 408 & 400 & 367 & 323 & 367 \\
$\begin{array}{l}\text { Oxygen content } \\
\text { (wet) }\end{array}$ & Weight (\%) & 9.12 & 9.12 & 9.12 & 8.82 & 8.96 & 9.12 \\
$\begin{array}{l}\text { Nitrogen content } \\
\text { (wet) }\end{array}$ & Weight (\%) & 3.38 & 3.38 & 3.38 & 4.1 & 3.76 & 3.38 \\
$\begin{array}{l}\text { SO } O_{2} \\
\begin{array}{l}\text { Soot } \\
\text { concentration }\end{array}\end{array}$ & 67.18 & 67.18 & 67.18 & 67.5 & 67.35 & 67.18 \\
$(6 \%)$ & Weight (\%) & 0.14 & 0.14 & 0.14 & 0.13 & 0.14 & 0.14 \\
\hline
\end{tabular}

\section{Establishment and Calculation of SCR Denitration System Model}

\subsection{Meshing and Setting Of Boundary Conditions}

After the establishment of the SCR model, the mesh is firstly divided to discretize the model, that is, the actual spatial continuous entity is described through a limited number of mesh nodes. After the grid is imported into the CFD calculation program, set the boundary conditions such as speed, pressure, temperature, and flue gas composition according to the actual situation. The entire calculation process is based on the solution of Navier Stockes flow control equations, and the most widely used engineering standard $\mathrm{k} \sim \varepsilon$ Turbulence model, when the iterative calculation reaches a certain convergence standard, the calculation process ends [9]. The total number of grids in the SCR model of this project is about 2.6 million. The grids are encrypted in small-scale spatial areas such as ammonia injection grids to ensure that the grids can accurately describe geometric entities after they are discretized. As shown in figure 1 (b).

The system boundary conditions are set according to the actual situation. In the inlet boundary conditions, parameters such as flow velocity, temperature and pressure of the flue gas are set according to the experimental data, and the outlet boundary conditions use the pressure outlet boundary and set it in the area where there is no backflow. The catalyst layer is simulated using the Porous media model, and the parameters are adjusted to ensure that the simulated resistance is close to the actual resistance. Ammonia injection uses the Species material transport model to simulate the mixing and diffusion of $\mathrm{NH}_{3}$ in the flue gas, but does not involve chemical reactions, and it is assumed that the NOx in the flue gas is uniformly distributed.

\subsection{Optimal Design of Deflector}

First, without any additional flow guiding device, simulate the flow field in the reactor and the flue. According to the uniformity of the flow field distribution, whether there is vortex backflow, etc., baffle groups are added at different positions to correct the unevenness of the flow field and achieve the design goal [10-11]. The flue gas flows in 
vertically from the lower section of the economizer and enters the horizontal flue through the first corner. Due to inertia, a large amount of flue gas sticks to the lower end of the horizontal flue, forming a high-speed area, so that the velocity field of the horizontal flue has a trend of up and down. Similarly, when the flue gas passes through the second corner, due to the kinetic energy of the flue gas, most of the flue gas sticks to the back wall of the vertical flue, so that the vertical flue forms a distribution of low front and high back. After passing through a short horizontal flue gas duct, the flue gas enters the reactor body along the inclined top of the reactor. A high-speed zone is formed on the back wall of the SCR reactor body, and this trend continues to the outlet. After calculation, the speed deviation before the first layer of catalyst is as high as $81 \%$. From the analysis of the velocity vector diagram, the upper part of the horizontal flue, the front part of the vertical flue, and the ash pipe flue gas all have different degrees of backflow. In the low-velocity zone of the main body of the reactor, a huge vortex is formed. Therefore, we need to determine the position and shape of the baffle according to the flow field simulated by the empty tower to eliminate the above-mentioned defects in the flow field.

According to the results of the flow field simulated by the empty tower, the straight baffle group 1 is arranged at the position where the speed of the lower part of the horizontal flue at the exit of the model economizer is the highest, a total of 3 pieces, which are used to raise a large amount of smoke close to the wall and balance the whole smoke Road flow. At the same time, an arc and straight baffle set is arranged at the turning corners of the horizontal flue and the vertical flue (this form of baffle has the smallest pressure loss and the best baffle effect at the right-angle corners) 2, 3 pieces in total. Used to guide the direction of air flow, correct the vertical upward flow direction of the flue gas, distribute the flue gas flow in the depth direction of the vertical flue, prevent the flue gas from sticking to the wall when transitioning to the vertical flue, and make the flue gas passing through the ammonia injection grille Try to be even. At the turning point of the vertical flue and the horizontal flue, a total of 3 sets of curved and straight baffles are arranged, a total of 3 pieces. The flue gas is uniformly transitioned from vertical to horizontal, and the flue gas is reasonably distributed to the horizontal flue in front of the inclined roof of the reactor. The deflector group 4 is arranged in the turning area at the entrance of the top section of the SCR reactor, a total of 3 pieces. It is used for the transition of the flue gas to the reactor inlet through the vertical flue and makes it beneficial to the uniform distribution of flue gas in the upper part of the reactor. A rectifying grid is arranged in the upper space of the top section of the reactor to correct the flow direction of the flue gas, improve the incidence angle of the flue gas at the inlet of the first layer catalyst, and optimize the distribution of the flue gas along the depth of the reactor. At the turning section of the vertical flue and the horizontal flue at the exit of the SCR reactor, there are two baffle groups 5 arranged. It is used to improve the distribution of the flue gas downstream of the catalyst to the outlet, which is more conducive to the flue gas entering the air preheater.

\subsection{Optimized Design of Ammonia Injection Grid (AIG)}

According to the actual situation of the project, after fully considering the length and layout of the front section of the flue, system pressure loss, mixing distance, operating cost and flexibility of operating layout, etc., it was decided to choose the linear control ammonia injection grid. According to the $95.2 \mathrm{~kg} / \mathrm{h}$ ammonia injection rate of each furnace provided by the power plant, the ammonia injection rate of a single reactor is 
$47.6 \mathrm{~kg} / \mathrm{h}$. Since the dilution wind of ammonia gas is at room temperature, $20^{\circ} \mathrm{C}$ is used, and the volume ratio of ammonia gas is $5 \%$. Under standard conditions, the density of ammonia gas is $0.759 \mathrm{~g} / \mathrm{L}$. According to the Avogadro formula PV=nRT, the density is $0.707 \mathrm{~g} / \mathrm{L}$, so the volume flow rate of the ammonia injection mixture is $\mathrm{v}=47.6 / 3600 / 0.707 / 5 \%=0.374 \mathrm{~m}^{3} / \mathrm{s}$, according to the flue gas flow velocity in the vertical direction, and to ensure a certain injection velocity of ammonia, the nozzle velocity of $25 \mathrm{~m} / \mathrm{s}$ is selected. The size of the vertical flue is $2 \times 10$ meters, so 6 unit grids are arranged. Each unit is composed of a main pipe and 4 branch pipes. Each branch pipe has 6 nozzles, and the nozzles are equipped with nozzles, which is more conducive to maintaining the direction and uniformity of the ammonia spray. The total number of ammonia injection points is $6 \times 4 \times 6=144$, and the opening radius is $\pi r^{2} \times 144 \times 25=0.374$, so $r=6 \mathrm{~mm}$. The simulation uses mixed ammonia gas with a volume fraction of 5\%, which is sprayed through 144 ammonia injection points, focusing on investigating the uniformity of the ammonia gas before reaching the first layer of catalyst. Figure 2 shows the distribution of the streamlines of ammonia injection in the SCR reactor and the uniformity of mixing before the first layer of catalyst. After calculation, the deviation of the ammonia concentration field is $7.5 \%$, which reaches the target, but there is still room for improvement.
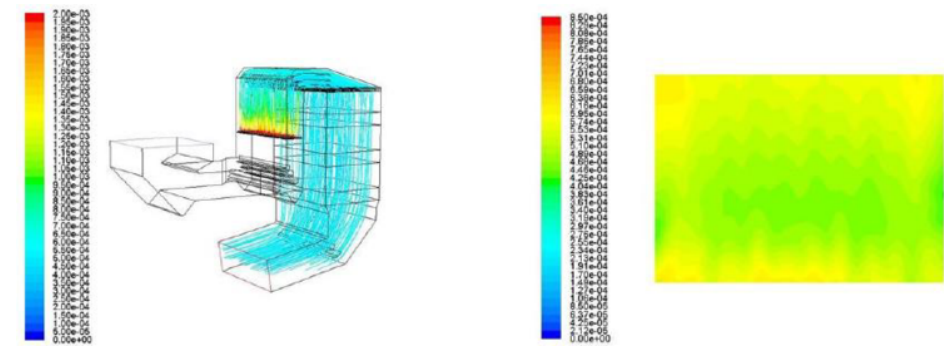

Figure 2. Ammonia mixing effect diagram.

\subsection{Optimal Design of Static Mixer}

This paper proposes a new type of static mixer. The mixer is composed of two equal $\mathrm{V}$-shaped grooves. The mixed gas sprayed from the ammonia injection point flows directly to the center intersection of the bottom of the tank. Theoretically, the airflow is divided into 8 parts, and each part is blocked by a triangular plate, forming turbulence and vortex. This research first proposes a design plan, and then changes its size, triangle angle, and installation position to find the best combination plan. First select a $40^{\circ}$ angle of inclination of the triangular plate and install it at a height of $0.5 \mathrm{~m}$ above the ammonia spray level. Take the length of the $\mathrm{V}$-shaped horizontal side of the mixer as $15 \mathrm{~cm}, 17.5 \mathrm{~cm}$, and $20 \mathrm{~cm}$ to investigate the mixer when the inclination angle and height are constant. The turbulence effect of the size on the flow field and the pressure loss. After the mixed gas flows out from the nozzle and reaches the center point of the bottom of the mixer, the airflow is divided into several streams. After each stream passes through the triangular plate of the side wing, a series of vortexes are generated. After that, it is combined again to complete the mixing process. The size of the concentration deviation is used to measure the mixing effect, and on this basis, the minimum pressure loss is expected.

The results show that the mixing distance has little difference in the effect of 
turbulence. Considering the convenience of installation, the installation of this mixer has the best effect at a distance of 0.5 meters from the ammonia injection surface. This design takes into account the actual situation of the project: the vertical flue section is long and there is enough space to install the static mixer; the overall structure is relatively simple, and the system pressure loss is small. In order to further improve the homogeneity of the molar ratio of ammonia to nitrogen, a static mixer is added. Compared with adjusting the amount of ammonia injection in different regions, this approach is more cost-effective, and at the same time greatly reduces the workload of operating adjustments.

\subsection{Simulation Results}

The CFD numerical simulation study of velocity distribution, NH3 concentration distribution, incident angle, system pressure drop, and temperature distribution was carried out under $100 \%$ BMCR load. It can be seen from figure 3(a) that the verticality of the upstream flow velocity of the first-layer catalyst is good, which meets the requirement that the incident angle is less than 10 degrees. It can be seen from figure 3(b) that the deviation of the temperature distribution upstream of the first-layer catalyst does not exceed $3^{\circ} \mathrm{C}$, which satisfies the requirement that the temperature deviation is less than $10^{\circ} \mathrm{C}$.
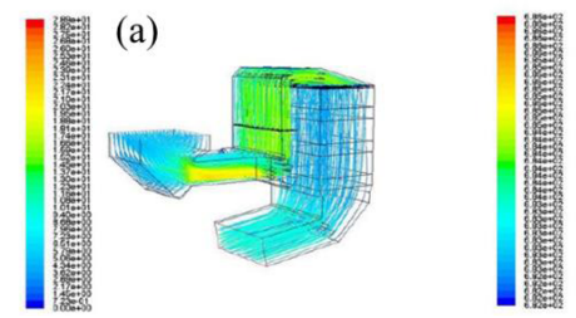

(b)

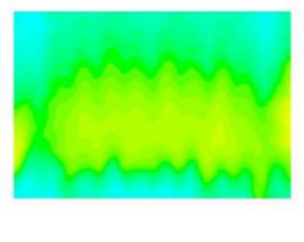

Figure 3. (a) Streamline diagram of SCR system, (b) Temperature distribution of SCR first layer catalyst.

The calibration simulation results under 75\% THA and 50\% THA conditions also show the similarity of the flow conditions. The verification simulation of $75 \%$ THA and $50 \%$ THA working conditions shows that the flue gas incident condition upstream of the first layer catalyst is similar to that under the $100 \% \mathrm{BMCR}$ working condition, which meets the requirement that the incident angle is less than 10 degrees. The verification simulation of 75\% THA and 50\% THA working conditions shows that the system pressure drop distribution is similar to that under $100 \%$ BMCR working conditions, and both meet the target requirements. In general, for $75 \%$ THA and $50 \%$ THA operating conditions, through simulation calculations, the flow fields of different operating conditions show a high degree of similarity, and all parameters meet the requirements of technical indicators. It can be seen that the previous design results have better adaptability to different working conditions.

\section{Conclusion}

When performing CFD numerical simulation on this SCR denitrification project, it is 
first necessary to simulate the original working conditions without baffles and rectifiers. According to the analysis of the original flow field, consider adding baffles where necessary. After ensuring that the fluid flow speed reaches a certain requirement, the design of the ammonia injection grid can be started to investigate its mixing effect. According to the actual situation of the project, fully considering the length and layout of the front flue, system pressure loss, mixing distance, operating cost and flexibility of operating layout, etc., it was decided to choose the linear control ammonia injection grid. In order to pursue a better mixing effect, in addition to optimizing AIG itself, you can also consider adding a static mixer. The vertical flue section of this project is long, and there is enough space to install the static mixer; the overall structure is relatively simple, and the system pressure loss is small.

In this paper, a new type of static mixer is designed, and the three aspects of size, inclination angle, and installation position are studied respectively, and a design scheme with the smallest pressure loss and the strongest turbulence effect is obtained. Compared with adjusting the amount of ammonia injection in different regions, this approach is more cost-effective, and at the same time greatly reduces the workload of operating adjustments. The actual unit will have load fluctuations during operation. After simulation, the flow field shows similarity under the conditions of $100 \%$ BMCR, $75 \%$ THA, and 50\% THA. It shows that the deflector and mixing device designed based on the full working conditions have high adaptability.

\section{References}

[1] Yang W, Wang B, Lei SY. Combustion optimization and NOx reduction of a $600 \mathrm{MWe}$ down-fired boiler by rearrangement of swirl burner and introduction of separated over-fire air. Journal of Cleaner Production. 2019 Nov; 210: 1120-1130.

[2] Yang W, Wang B, Xiang DX. Study on the control target and countermeasure of coal consumption in Wuhan. China population, resources and environment. 2018 Aug; 28(S1): 9-12.

[3] Zhang X, Chen ZC, Zhang MD. Combustion stability, burnout and NO emissions of the 300-MW down-fired boiler with bituminous coal: Load variation and low-load comparison with anthracite. Fuel. 2021 Mar; 295: 120641.

[4] Jiang Y, Gao X, Wu WH. Review of the deactivation of selective catalytic reduction DeNOx catalysts. Proceedings of the CSEE. 2013 Apr; 33(14):18-31.

[5] Wang YS, Zhang L, Chen JH. The harm and treatment of nitrogen oxide in the atmosphere. Technology Innovation and Application. 2019 Mar; 7:137-138.

[6] Pei YK. Optimization study on ammonia injection and mixing device of SCR system. Hangzhou: Zhejiang University; 2013 January; 01 p. 32.

[7] Zhao Q. Simulation optimization and optimal control on spraying ammonia of SCR flue gas denitrification. Chongqing: Chongqing University; 2012 April; 01. p.46.

[8] Zhang DJ, Ma ZR, Sun Q. Progress in the mechanism of selective catalytic reduction (SCR) reaction. Chemical industry and engineering progress. 2019 Apr; 38(4).

[9] Wang WS, Shang-guan SS, Yao MY. Design and optimization of guide vanes in a $300 \mathrm{MW}$ coal-fired boiler SCR system. Journal of China Coal Society. 2015 Jul; 40(7): 1634-1640.

[10] Zhu WB, Wei Y. Research on cold model experiment and CFD numerical calculation of SCR flue gas denitrification device in coal-fired power plant. Equipment machinery. 2013Jun; (2): 58-65.

[11] Liu H. Numerical simulation and optimization research of flow field for a SCR De-NOx reactor of a coal-fired boiler. Changsha: Changsha University of Science and Technology; 2013 April; 01 p. 43. 